\section{Commentary: The price of pleurodesis: The impact of pleurodesis on lung function}

\author{
Saurav Adhikari, MD, and Siva Raja, MD, PhD, FACS
}

Pleurodesis for the purpose of achieving pleural symphysis is commonly done in most thoracic surgical practice. This technique is used to resolve prolonged air leaks, persistent pleural effusions, and recurrent spontaneous pneumothorax. ${ }^{1}$ In fact, this can be a "knee jerk" solution to the aforementioned problems. However, the presence of a potential space in the pleura with trace amounts of pleural fluid is thought to optimize the mechanics of respiration by allowing the visceral pleural and the parietal pleura to slide over one another. Perhaps it is time to consider the price one pays for this treatment strategy.

In this issue of the Journal, Kagimoto and colleagues ${ }^{2}$ examine the effect of pleurodesis primarily for postoperative alveolar pleural fistulas after segmentectomies. The authors note an approximate $5.5 \%$ difference in vital capacity at 6 months, which persisted at 12 months. Although not statistically significant, there appears to be a similar trend in forced expiratory volume in 1 second, at least at 6 months. Given the likely pleural symphysis, this type of restrictive pattern makes biological sense. Furthermore, the use of talc appears to be more detrimental than other agents, such as $\mathrm{OK} 32 .^{3}$ Given the robust talc reaction that can occur, ${ }^{4}$ this too is expected.

Although this study clearly points to some penalty from pleurodesis, the series is relatively small, with only 39 patients undergoing pleurodesis. This small number is perhaps the reason for the trends without statistical significance.

\footnotetext{
From the Department of Thoracic and Cardiovascular Surgery, Heart and Vascular Institute, Cleveland Clinic, Cleveland, Ohio.

Disclosures: The authors reported no conflicts of interest.

The Journal policy requires editors and reviewers to disclose conflicts of interest and to decline handling or reviewing manuscripts for which they may have a conflict of interest. The editors and reviewers of this article have no conflicts of interest.

Received for publication Jan 10, 2021; revisions received Jan 10, 2021; accepted for publication Jan 13, 2021; available ahead of print Feb 18, 2021.

Address for reprints: Siva Raja, MD, PhD, FACS, Department of Thoracic and Cardiovascular Surgery, Heart and Vascular Institute, Cleveland Clinic Foundation, J4-1, 9500 Euclid Ave, Cleveland, OH 44195 (E-mail: rajas@ ccf.org).

JTCVS Open 2021;5:119-20

2666-2736

Copyright (C) 2021 The Authors. Published by Elsevier Inc. on behalf of The American Association for Thoracic Surgery. This is an open access article under the CC BY-NCND license (http://creativecommons.org/licenses/by-nc-nd/4.0/).

https://doi.org/10.1016/j.xjon.2021.01.006
}

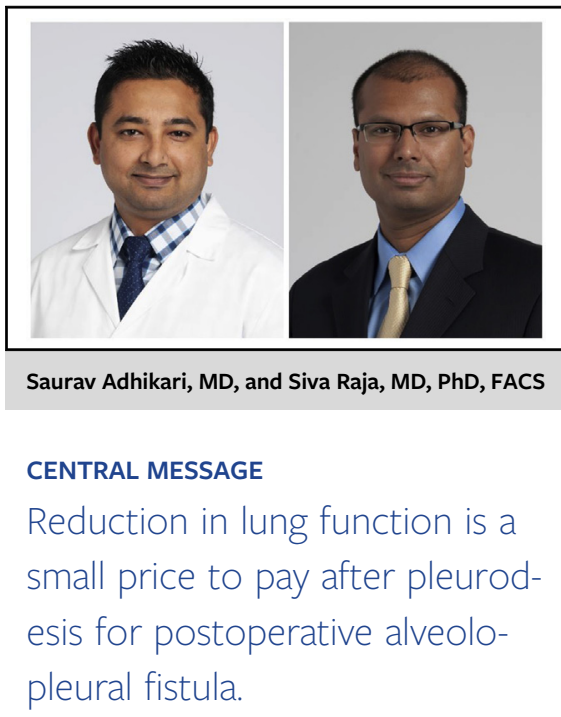

Similarly, the lack of a single agent use or any standardized protocol introduces variability that can account for the wider range of data. So for these reasons, we are unable to further drill down on the true cost of pleurodesis. Adding to this cost are adverse events pertaining to use of specific agents, which the authors have not reported for their patients.

Everything in life comes with a price. Here we see that with pleurodesis. However, there is also a cost for prolonged air leaks, such as empyema, increased discomfort from tube thoracostomy, and increased cost of hospitalization. Although not specifically examined here, similar penalties for pleural effusion also exist. Alternate solutions to solve these common problems that do not resolve within a reasonable timeframe are often in the form of surgical procedures. Repeat surgery carries with it its own set of morbidities. Finally, this study examines the penalty only through the lens of alterations in pulmonary function tests. Based on the agent used, there is a physical cost to the patient as well. Specifically, a talc reaction can result acute respiratory distress and doxycycline can cause significant pain. ${ }^{4,5}$ Regardless, pleurodesis seems to be the lesser of 2 evils. As such, when used, its use is almost always indicated.

This study and others suggest that at least the cost of pleurodesis is likely minimal: $5.5 \%$ here. To put this in perspective, this small incremental reduction in lung function is not likely to affect most individuals in accomplishing the activities of daily living. This technique also has the best riskreward profile compared with alternative therapies. Thus, although there is a cost to pleurodesis, it is fortunately small, and most of us can afford to pay it! 


\section{References}

1. Lamb C, Li A, Thakkar D, Lee P. Pleurodesis. Semin Respir Crit Care Med. 2019; 40:375-85.

2. Kagimoto A, Tsutani Y, Hirai Y, Handa Y, Mimae T, Miyata Y, et al. Impact of postoperative pleurodesis on pulmonary function after lung segmentectomy. $J$ Thorac Cardiovasc Surg Open. 2021;5:110-8.
3. Muta F, Takamori S, Matsuo T, Iwasaki Y, Yoshiyama K, Shirouzu K. Changes in the pleural cavity by pleurodesis using talc or OK-432: an experimental study. Surg Today. 2011;41:111-4.

4. Baiu I, Yevudza E, Shrager JB. Talc pleurodesis: a medical, medicolegal, and socioeconomic review. Ann Thorac Surg. 2020;109:1294-301.

5. Shaw PH, Agarwal R. Pleurodesis for malignant pleural effusions. Cochrane Database Syst Rev. 2004;CD002916. 